\title{
Identification and antioxidant activity of carotenoids from superfine powder of Rhodobacter Sphaeroides
}

\author{
Zuming Li ${ }^{1}$, Lina Kong ${ }^{1}$, Bodi Hui', Xiaoya Shang ${ }^{1}$, Liping Gao', Na Luan', Xuliang Zhuang ${ }^{2,3}$, Dong Wang ${ }^{4}$, \\ Zhihui Bai ${ }^{2,3^{*}}$ \\ ${ }^{1}$ Department of Food Science and Beijing Key Laboratory of Bioactive Substances and Functional Foods, College of Biochemical Engineering, \\ Beijing Union University, Beijing, China, ${ }^{2}$ Research Center for Eco-Environmental Sciences, Chinese Academy of Sciences, Beijing, China, \\ ${ }^{3}$ College of Resources and Environment, University of Chinese Academy of Sciences, Beijing, China, ${ }^{4}$ Wuxi Zhongke Huoli Biotechnology Co., \\ LTD, Yixing City, Jiangsu Province, China
}

\section{A B S T R A C T}

\begin{abstract}
The interest in carotenoids from the natural-antioxidant point of view has recently risen sharply because of their substantial health benefits. Here, we report the identification and antioxidant activity of carotenoids extracted by superfine grinding from Rhodobacter sphaeroides 3757 which is a species of photosynthetic bacteria. After separation and purification by silica gel column chromatography and reversed-phase high performance liquid chromatography (RP-HPLC), the four major carotenoids from the superfine powder of $R$. sphaeroide 3757 were identified as bixin, hydroxyspheroidenone, 3,3,4ל-tetrahydrospirilloxanthin-20-al, and spheroidenone by reversed phase - high performance liquid chromatography - atmospheric pressure chemical ionization - mass spectrometry (RP-HPLC-APCI-MS). The antioxidant activity of the carotenoids extracted after superfine grinding of dry biomass of $R$. sphaeroide 3757 was higher than that after ultrasonic treatment. When the ratio solvent-to-solid was 30, 2,2-diphenyl-1-picrylhydrazyl (DPPH) radical-scavenging activity, reducing power, and lipid peroxidation inhibitory activity of the extracts after superfine grinding were $74.0 \% \pm 3.1 \%, 0.497 \pm 0.022$, and $77.6 \% \pm 3.2 \%$, respectively. By contrast, the extracts after ultrasonic treatment, these numbers were $61.0 \% \pm 2.5 \%, 0.328 \pm 0.014$, and $55.2 \% \pm 2.3 \%$, respectively. These results indicate that carotenoids from $R$. sphaeroide 3757 show a significant antioxidant activity in vitro in a concentration-dependent manner, and that superfine grinding is the optimal extraction method. We hope to provide scientific guidance for commercial production of natural- antioxidant and functional food from carotenoids of $R$. sphaeroide.
\end{abstract}

Keywords: Rhodobacter sphaeroides; Carotenoids; Superfine grinding; HPLC-DAD-APCI-MS; Antioxidant activity

\section{INTRODUCTION}

Carotenoids represent a vital class of lipid-soluble functional compounds and are widely distributed in plants, animals and microbes (Liu et al., 2014). Carotenoids have been described as possessing several important functional properties, mainly an antioxidant activity as well as prevention of cardiovascular diseases, cancer, and macular degeneration and in some cases, provitamin A activity (Giuffrida et al., 2013; Kljak and Grbeša, 2015). These properties make carotenoids ideal for the ever growing functional food industry as well as for promotion of the consumption of natural products in which these compounds are present (Giuffrida et al., 2013). Currently, most of the carotenoids sold on the market are synthesized chemically and cannot meet consumers' demand for natural carotenoids. Thus, researchers shifted attention from chemical synthesis to isolation of carotenoids from biological sources (Yoo et al., 2016). Therefore, commercial production of carotenoids using carotenoid-producing microorganisms has been taken into consideration owing to the highly efficient and easy manipulation of processing schemes (Liu et al., 2015; Yoo et al., 2016). Some studies have been reported in the last few years on carotenoid synthesis by microorganisms (Chiu and Liu, 2014; Liu et al., 2015; Yoo et al., 2016).

Rhodobacter sphaeroides, being highly versatile, has attracted considerable attention in energy, environment, breeding, food and pharmaceutical industries because it can grow under either aerobic or anaerobic respiration, fermentation, or photosynthesis conditions (Chiu and Liu, 2014). R. sphaeroides is a species of photosynthetic bacteria that are nontoxic. A commercial carotenoid product from the extract of probiotic

\footnotetext{
*Corresponding Author: Zhihui Bai, Research Center for Eco-Environmental Sciences, Chinese Academy of Sciences, Beijing 100085, China. Tel: +86-10-6284-9156, Fax: +86-10-6284-9155, E-mail: zhbai@rcees.ac.cn
} 
R. sphaeroides mutant strain WLAPD911 has been used to enhance tilapia growth performance via immune regulation (Li et al., 2016). In light of the impact of carotenoids on human health, it is crucial to devise an appropriate technique for quantification of various carotenoids in $\mathrm{R}$. sphaeroides (Liu et al., 2014). Liquid chromatography coupled with tandem mass spectrometry (HPLC-MS/MS) is becoming more and more popular as a tool for identification of bioactive substances because of its high specificity and sensitivity as well as excellent separation of target compounds (Wang et al., 2012; Sánchez et al., 2016). Atmospheric pressure chemical ionization(APCI) has become the most widely used ionization technique for carotenoids and shows high sensitivity for their analysis (Rivera and Canela-Garayoa, 2012). Nevertheless an analysis of carotenoids in $R$. sphaeroides by high performance liquid chromatography photo diode array detection - atmospheric pressure chemical ionization - mass spectrometry (HPLC-DAD-APCI-MS) has not been conducted so far.

After superfine grinding, the solubility of nutritive components increases, and they are easily absorbed by the human body (Lee et al., 2013). In recent years, the possible use of micro- or nanotechnology in food research attracted much attention and became the focus of research in many countries (Zhu et al., 2010; Lee et al., 2013). While research on this topic is limited (Zhao et al., 2015; Ramachandraiah and Chin, 2016). Many studies have revealed that oxidative stress plays an important role in the pathogenesis of various chronic diseases, such as diabetes, cancer, and cardiovascular diseases, and it has been suggested that antioxidants perform a protective function against various diseases by defending cells against oxidative damage (Ma et al., 2016; Venetsanou et al., 2017). More recently, growing interest has been focused on the natural antioxidant compounds present in plants, animals, and even microbes (Ramachandraiah and Chin, 2016; Sequeda-Castañeda et al., 2016; Silva and Lidon. 2016; Manzano et al., 2017). So far, the antioxidant activities of the carotenoids extracted from superfine powder of R. sphaeroides remain unknown.

The aim of this study was to explore the identification of major carotenoids of superfine powder from R. sphaeroides by HPLC-DAD- APCI-MS. We also compared the effects of superfine grinding technology and of ultrasonic technology on the antioxidative properties of carotenoids from R. sphaeroides.

\section{MATERIALS AND METHODS}

\section{Materials and reagents}

A strain of photosynthetic bacterium R. sphaeroides 3757 was stored by the China General Microbiological Culture Collection Center, CGMCC No. 3757.
Most of the solvents and chemicals used here were of analytical grade, and were purchased from Beijing Chemical Reagents Company. Biological reagents were purchased from Beijing Dingguo Changsheng Biotechnology Co. Ltd.. Acetonitrile $(\mathrm{MeCN})$, methanol $(\mathrm{MeOH})$, and methyl tert-butyl ether (MTBE) used during HPLC analysis were of HPLC grade, and were purchased from Dikma Technologies, Beijing, China. Silica gel GF254 for TLC was obtained from Qingdao Haiyang Chemical Company, Quingdao, China.

\section{Preparation of dry biomass from $\boldsymbol{R}$. sphaeroides}

For the seed culture, R. sphaeroides 3757 was inoculated into the seed medium for $24 \mathrm{~h}$ and shaken at $180 \times \mathrm{g}$ and $32{ }^{\circ} \mathrm{C}$. The composition of the seed medium was as follows (g/L): Glucose 20, yeast extract powder 10, tryptone 10 , sodium chloride 5 . The fermentative medium was composed of the following substances $(\mathrm{g} / \mathrm{L})$ : sodium malate 4, glucose $20,\left(\mathrm{NH}_{4}\right)_{2} \mathrm{SO}_{4} 7$, yeast extract powder $10, \mathrm{~K}_{2} \mathrm{HPO}_{4} 0.9, \mathrm{KH}_{2} \mathrm{PO}_{4} 0.6$, a growth factor solution $(10 \mathrm{~mL})$ consisting of vitamin $\mathrm{B}_{1} 1.0(\mathrm{~g} / \mathrm{L})$, vitamin $\mathrm{PP}$ $1.0(\mathrm{~g} / \mathrm{L})$, and vitamin H $0.016(\mathrm{~g} / \mathrm{L})$. After inoculation with $10 \%(\mathrm{v} / \mathrm{v})$ of the seed liquid, the cultures were incubated for $40 \mathrm{~h}$ at $180 \times \mathrm{g}$ and $32^{\circ} \mathrm{C}$. After centrifuged at $7000 \times \mathrm{g}$ for $10 \mathrm{~min}$, the sediment was collected and washed twice with distilled water, then dried in a Laboratory freeze-dryer (Biocool Company, China) for $72 \mathrm{~h}$ at $-50{ }^{\circ} \mathrm{C}$ and pressure $<1 \mathrm{~Pa}$.

\section{Superfine grinding and ultrasonic treatment}

The dry biomass of R. sphaeroides 3757 was ground into superfine powder at $4{ }^{\circ} \mathrm{C}$ for $8 \mathrm{~h}$ in the superfine grinder (Taijihuan company, China). $5 \mathrm{~g}$ of a superfine powder sample was mixed with acetone in different ratios of solvent to solid in a flask and ultrasonically processed in an ultrasonic cleaner $\left(25^{\circ} \mathrm{C}\right)$ for $1 \mathrm{~h}$.

After the dry biomass of R. sphaeroides was mixed with acetone in a $10-\mathrm{mL}$ container, the carotenoids were extracted by an ultrasonic crasher (Sonics \& Materials Inc. USA) in various ratios of solvent to solid. And the ultrasonic amplitude, work/rest time, and duration were set to $30 \%, 30 \mathrm{~s} / 30 \mathrm{~s}$, and $10 \mathrm{~min}$, respectively. Then the sample was incubated in an ultrasonic cleaner $\left(25^{\circ} \mathrm{C}, 1 \mathrm{~h}\right)$.

Finally, the samples were centrifuged at $12000 \times \mathrm{g}$ for 10 min to obtain the supernatant containing carotenoids.

\section{Extraction and separation of carotenoids}

The carotenoids were extracted from $5 \mathrm{~g}$ superfine powder of R. sphaeroides 3757 as described above with the ratio of solvent to solid at 25. The extraction procedure was repeated until the supernatant became colorless. Then all the supernatants were pooled and concentrated in a rotary 
evaporator $\left(\mathrm{T}<30^{\circ} \mathrm{C}\right)$, flushed with $\mathrm{N}_{2}$, and kept at $-20^{\circ} \mathrm{C}$ in the dark until separation. All the extraction procedures were conducted in triplicate.

The concentrated extract was applied to a silica gel column, and carotenoids were eluted using increasing percentages of acetone in petroleum ether. Thirteen fractions were collected according to thin layer chromatography (TLC) analysis with a mixture of petroleum ether: Acetone (10:1 $\mathrm{v} / \mathrm{v}$ ) as the developing agent. The fractions were evaporated to dry, dissolved in acetone, passed through a $0.22-\mu \mathrm{m}$ membrane filter for further analysis.

Further separation of carotenoids was performed using an Agilent 1260 Series system equipped with a DAD. The chromatographic analysis was conducted on a YMC carotenoid C30 column $(250 \mathrm{~mm} \times 4.6 \mathrm{~mm}$ internal diameter, i.d.)(Waters, USA). The injection volume was $20 \mu \mathrm{L}$. The mobile phase was $\mathrm{MeCN}: \mathrm{MeOH}$ (solution A) $(3: 1, v / v)$ and MTBE (solution B). Samples were initially eluted with $100 \%$ of A, changing by gradient to $20 \%$ of $\mathrm{A}$ and $80 \%$ of $\mathrm{B}$ in $20 \mathrm{~min}$. The flow rate was $1 \mathrm{~mL} / \mathrm{min}$. DAD detection was performed at $480 \mathrm{~nm}$.

The 300-650 nm absorbance spectra of the main carotenoids were acquired by means of a Waters 1525 HPLC system and 2996 PDA detector (Waters, USA).

\section{HPLC-APCI-MS/MS analysis}

LC-MS was performed on a Thermo LTQ XL mass spectrometer (Thermo Fisher, USA) connected to an Agilent 1200 HPLC system and DAD detector (Agilent, USA). The HPLC analytical method for carotenoids has been described above. Carotenoids were detected with APCI in the positive-ionization mode. Source conditions were set as follows: Capillary temperature $300{ }^{\circ} \mathrm{C}$, source voltage $4.5 \mathrm{kV}$, and capillary voltage $25 \mathrm{~V}$. Nitrogen was utilized as the sheath gas and set to 50 arb for the positive mode. Nitrogen also served as an auxiliary gas and sweep gas, set to 5 arb, respectively. Full scan (100-1000) and iontrap MS/MS of the most intense ion from the parent mass list were carried out using CID with a normalized collision energy of 35. Identification of major carotenoids from R. sphaeroides 3757 was based upon the chromatographic elution on a C30 HPLC column, spectrum characteristics, and mass spectral characteristics.

\section{DPPH radical-scavenging activity}

The (2,2-diphenyl-1-picrylhydrazyl) DPPH inhibition by carotenoids extracted from dry biomass of $R$. sphaeroides 3757 after superfine grinding or ultrasonic treatment was measured according to the method reported previously (Xia et al., 2012; Zhuang et al., 2013).

\section{Reducing power}

The reducing power of carotenoids was assayed according to the method reported elsewhere (Xia et al., 2012).

\section{Lipid peroxidation-inhibitory activity}

This activity of carotenoids was measured in a linoleic acid emulsion system according to the method reported previously (Zhuang et al., 2013).

\section{Statistical analysis}

The statistical software SPSS18.0 (IBM, USA) was used. Means and standard deviations were calculated.

\section{RESULTS}

\section{Particle size}

Small-angle X-ray scattering (SAXS) analysis is an effective method by which the particle size distribution of an ultrafine powder in a sample can be determined (Zhu et al., 2010). All the particle sizes of superfine powder from R. sphaeroides 3757 determined by the SAXS method were below $620 \mathrm{~nm}$, while $87.8 \%$ of the particle sizes were below $300 \mathrm{~nm}$. These results revealed that pulverization by high-energy-nano-ball-milling can effectively reduce sizes of the particles of R. sphaeroides 3757 to a submicron range to manufacture ultrafine powder. Similarly, it has been reported that the particle size of nanopowdered ginseng (NPG) is in the range 600 to $1000 \mathrm{~nm}$ (Lee et al., 2013). Therefore, carotenoids of superfine powder from R. sphaeroides 3757 can be easily dispersed into a solution, and the yield considerably increased.

\section{Separation of the major carotenoids}

It has been well documented that a C30 column is superior to $\mathrm{C} 18$ column in terms of simultaneous separation of both positional and geometrical isomers of carotenoids because of greater hydrophobic interaction between carotenoid isomers and the C30 stationary phase (Liu et al., 2014). Due to the complexity of carotenoids in photosynthetic bacteria, a gradient solvent system consisting of acetonitrile/ methanol $(3: 1, \mathrm{v} / \mathrm{v})$ and MTBE (as described above) was developed on the basis of a RP-C30 stationary phase, and four main carotenoids from R. sphaeroides 3757 were completely resolved within $20 \mathrm{~min}$. The representative chromatograms of the four major carotenoids are illustrated in Supplemental Fig. 1 and Table 1, and their retention times were $17.571,16.689,8.432$, and 15.480 min, respectively.

\section{Structure elucidation of major carotenoids}

The chromatographic elution on a C30 HPLC column, spectrum characteristics, and mass spectral characteristics are shown in (Supplemental Figs. 1-6 and Table 1). The structure elucidation of unknown major carotenoids was 
Table 1: Chromatographic and UV-vis spectra and mass characteristics of carotenoids from $R$. sphaeroides 3757 obtained by RP-HPLC-APCI-MS/MS

\begin{tabular}{|c|c|c|c|c|c|}
\hline Carotenoid & RT $(\min )^{a}$ & $\lambda_{\text {max }}(n m)^{b}$ & {$[\mathrm{M}+\mathrm{H}]^{+}(\mathrm{m} / \mathrm{z})$} & $M S(+)(m / z)^{c}$ & $M^{2}(+)(m / z)^{d}$ \\
\hline Spheroidenone & 17.571 & 376,485 & 583 & $\begin{array}{c}551[\mathrm{M}+\mathrm{H}-32], 491[\mathrm{M}+\mathrm{H}-92] \\
477[\mathrm{M}+\mathrm{H}-106]\end{array}$ & $551[\mathrm{M}+\mathrm{H}-32]$ \\
\hline $\begin{array}{l}3,4,3^{\prime}, 4^{\prime} \text {-Tetrah- } \\
\text { ydrospirilloxant-hin-20-al }\end{array}$ & 16.689 & 370,485 & 615 & $\begin{array}{c}583[\mathrm{M}+\mathrm{H}-32], 551[\mathrm{M}+\mathrm{H}-32-32] \\
509[\mathrm{M}+\mathrm{H}-106], 477[\mathrm{M}+\mathrm{H}-106-32] \\
445[\mathrm{M}+\mathrm{H}-32-32-106] \\
385[\mathrm{M}+\mathrm{H}-32-92-106]\end{array}$ & $583[\mathrm{M}+\mathrm{H}-32]$ \\
\hline Bixin & 8.432 & $358,460,486$ & 395 & $363[\mathrm{M}+\mathrm{H}-32]$ & $\begin{array}{c}377[\mathrm{M}+\mathrm{H}-18], 363[\mathrm{M}+\mathrm{H}-32], \\
345[\mathrm{M}+\mathrm{H}-32-18], \\
335[\mathrm{M}+\mathrm{H}-32-28], \\
317[\mathrm{M}+\mathrm{H}-32-28-18], \\
289[\mathrm{M}-106]\end{array}$ \\
\hline Hydroxysphero-idenone & 15.480 & 375,484 & 601 & $\begin{array}{c}583[\mathrm{M}+\mathrm{H}-18], 569[\mathrm{M}+\mathrm{H}-32], \\
509[\mathrm{M}+\mathrm{H}-92,495[\mathrm{M}+\mathrm{H}-106], \\
477[\mathrm{M}+\mathrm{H}-18-106], \\
385[\mathrm{M}+\mathrm{H}-18-92-106]\end{array}$ & $583[\mathrm{M}+\mathrm{H}-18]$ \\
\hline
\end{tabular}

Retention time on the C30 column, binear gradient of acetonitrile-methanol (3:1)/MTBE, 'In MS, the most abundant ion is shown in boldface, ${ }^{\text {IIn MS/ }}$ MS, the most abundant ion is shown in boldface

Table 2: Formulas and chemical structures of carotenoids from $R$. sphaeroides 3757

\begin{tabular}{|c|c|c|}
\hline Carotenoid & Formula & Chemical structure \\
\hline Spheroidenone & $\mathbf{C}_{41} \mathbf{H}_{58} \mathbf{O}_{2}$ & \\
\hline $\begin{array}{l}3,4,3^{\prime}, 4^{\prime} \text {-Tetrahydro- } \\
\text { spirilloxanthin-20-al }\end{array}$ & $\mathrm{C}_{42} \mathrm{H}_{6} 2 \mathrm{O}_{3}$ & \\
\hline Bixin & $\mathbf{C}_{25} \mathbf{H}_{30} \mathbf{O}_{4}$ & \\
\hline Hydroxyspheroidenone & $\mathbf{C}_{41} \mathbf{H}_{60} \mathbf{O}_{3}$ & \\
\hline
\end{tabular}

undertaken according to their chromatographic behaviors (such as retention time), electronic absorption spectral characteristics (e.g. the maximum absorption wavelength and spectral shapes) and mass spectral characteristics (e.g. the $\mathrm{m} / \mathrm{z}$ value of parent ions and the pattern of fragmentation), in comparison with those of published data (Sánchez et al., 2016).

Spheroidenone $(\mathrm{Rt}=17.571 \mathrm{~min})$ : This is a major carotenoid produced by $R$. sphaeroides during anaerobic or aerobic growth (Yeliseev and Kaplan, 1997; Chi et al., 2015). The identification of this carotenoid $(\mathrm{Rt}=17.571 \mathrm{~min})$ was based on the UV-visible spectrum characteristics (Table 1). This carotenoid has a UV-visible spectrum with $\lambda_{\max }$ at $485 \mathrm{~nm}$ Supplemental Fig. 2; the shape of the spectrum was similar to that of spheroidenone (Takaichi et al., 1991). Furthermore, this carotenoid was identified as spheroidenone by comparing the mass spectra with those given in the literature (Enzell et al., 1969). The mass spectra of this carotenoid obtained in the positive ion mode (Table 1) showed a protonated molecule at $\mathrm{m} / \mathrm{z} 583$ and fragment ions in the MS/MS at $\mathrm{m} / \mathrm{z} 551[\mathrm{M}+\mathrm{H}-32]^{+}, \mathrm{m} / \mathrm{z} 491[\mathrm{M}+\mathrm{H}-92]^{+}$, and $\mathrm{m} / \mathrm{z} 477$ $[\mathrm{M}+\mathrm{H}-106]^{+}$Supplemental Fig. 3, corresponding to the loss of one methoxy group, toluene group, and xylene from the polyene chain, respectively.

3,4,3',4'-Tetrabydrospirilloxanthin-20-al (Rt = $16.689 \mathrm{~min})$ : This carotenoid was identified considering the UV-visible and mass spectral characteristics. In the positive ion mode (Table 1 ), the mass spectra showed a protonated molecule at $m / z 615$ and fragments at $\mathrm{m} / \mathrm{z} 583[\mathrm{M}+\mathrm{H}$ $32]^{+}, \mathrm{m} / \mathrm{z} 551[\mathrm{M}+\mathrm{H}-32-32]^{+}, \mathrm{m} / \mathrm{z} 509[\mathrm{M}+\mathrm{H}-106]^{+}$, $\mathrm{m} / \mathrm{z} 477[\mathrm{M}+\mathrm{H}-106-32]^{+}, \mathrm{m} / \mathrm{z} 445[\mathrm{M}+\mathrm{H}-32-32-106]^{+}$, and $\mathrm{m} / \mathrm{z} 385[\mathrm{M}+\mathrm{H}-32-92-106]^{+}$Supplemental Fig. 4, corresponding to the loss of one methoxy group, two methoxy groups, xylene, one methoxy group + xylene, and two methoxy groups + xylene from the polyene chain, respectively. These mass spectral characteristics of 3,4,3',4'-tetrahydrospirilloxanthin-20-al have already been reported in the literature (Francis and Liaaen-Jensen, 1970). 
Bixin $(\mathrm{Rt}=8.432 \mathrm{~min})$ : This carotenoid was identified by comparing the UV-visible spectrum $\left(\lambda_{\text {max }}\right.$ at 358,460 , $486 \mathrm{~nm}$ ) (Supplemental Fig. 2 and Table 1) with that given in the database. In the positive ion mode (Table 1), the mass spectra showed a protonated molecule at $\mathrm{m} / \mathrm{z} 395$ and the most abundant fragment ion in the MS/MS spectrum at $\mathrm{m} / \mathrm{z} 363\left([\mathrm{M}+\mathrm{H}-32]^{+}\right)$, corresponding to cleavage of the methoxy group. The mass spectra showed the fragment ions $\mathrm{m} / \mathrm{z} 377[\mathrm{M}+\mathrm{H}-18]^{+}, \mathrm{m} / \mathrm{z} 363[\mathrm{M}+\mathrm{H}-32]^{+}, \mathrm{m} / \mathrm{z}$ $345[\mathrm{M}+\mathrm{H}-32-18]^{+}, \mathrm{m} / \mathrm{z} 335[\mathrm{M}+\mathrm{H}-32-28]^{+}, \mathrm{m} / \mathrm{z} 317$ $[\mathrm{M}+\mathrm{H}-32-28-18]^{+}$, and $\mathrm{m} / \mathrm{z} 289$ [M-106] $^{+}$, corresponding to the loss of $\mathrm{H}_{2} \mathrm{O}, \mathrm{CH}_{3} \mathrm{OH}, \mathrm{CH}_{3} \mathrm{OH}+\mathrm{H}_{2} \mathrm{O}, \mathrm{CH}_{3} \mathrm{OH}+$ $\mathrm{CO}, \mathrm{CH}_{3} \mathrm{OH}+\mathrm{CO}+\mathrm{H}_{2} \mathrm{O}$, and xylene from the polyene chain, respectively Supplemental Fig. 5. This fragmentation pattern for bixin has already been reported in the literature (Takaichi et al., 1993; Chiste et al., 2011).

Hydroxyspheroidenone $(\mathrm{Rt}=15.480 \mathrm{~min})$ : This carotenoid was tentatively identified as hydroxyspheroidenone by comparing the UV-visible spectrum with that given in the database and literature (Manwarning et al., 1980). Moreover, the mass spectra of this carotenoid obtained in the positive ion mode (Table 1) showed the protonated molecule at $\mathrm{m} / \mathrm{z} 601$ and fragment ions in the MS/MS spectrum at $\mathrm{m} / \mathrm{z} 583[\mathrm{M}+\mathrm{H}-18]^{+}, \mathrm{m} / \mathrm{z} 569[\mathrm{M}+\mathrm{H}-32]^{+}, \mathrm{m} / \mathrm{z} 509$ $[\mathrm{M}+\mathrm{H}-92]^{+}, \mathrm{m} / \mathrm{z} 495[\mathrm{M}+\mathrm{H}-106]^{+}, \mathrm{m} / \mathrm{z} 477[\mathrm{M}+\mathrm{H}-18-$ $106]^{+}$, and $385[\mathrm{M}+\mathrm{H}-18-92-106]^{+}$, corresponding to the loss of one hydroxyl group, methoxy group, toluene group, xylene, $\mathrm{H}_{2} \mathrm{O}+$ xylene, and $\mathrm{H}_{2} \mathrm{O}+$ toluene + xylene from the polyene chain, respectively.

The formulas and molecular structures of the four major carotenoids from superfine powder of R. sphaeroides 3757 are shown in Table 2.

\section{Antioxidant properties}

The antioxidant properties of carotenoids extracts obtained by either superfine grinding (ESG) or ultrasonic treatment (EUT) from superfine powder of R. sphaeroides 3757 were evaluated based on their in vitro indexes including $\mathrm{DPPH}$ radical-scavenging activity, reducing power and lipid peroxidation-inhibitory activity, and the results are shown in Fig. 1.

The assay for activity of scavenging of DPPH radicals is a widely used, easy-to-perform, and highly reproducible method for testing the antiradical activity of a large variety of compounds and natural extracts (Stajc 'ic' et al., 2015; Zarza-García et al., 2017). As shown in Fig. 1, all the extracts showed a concentration-dependent DPPH radicalscavenging activity. The scavenging activity increased with the increase in the concentration of dry biomass of R. sphaeroides 3757. The ESG samples showed higher DPPH radical-scavenging activity than EUT samples did. When the ratio solvent-to-solid was 30, the scavenging activities of ESG and EUT samples were $74.0 \% \pm 3.1 \%$ and $61.0 \%$ $\pm 2.5 \%$, respectively.

The reducing-power assay is often used to evaluate the ability of natural antioxidants to donate an electron or hydrogen (Xia et al., 2012). As shown in Fig. 1, the ESG samples possessed higher reducing power than EUT samples did. When the ratio solvent-to-solid was 30 , the reducing power of the ESG and EUT samples was $0.497 \pm 0.022$ and $0.328 \pm 0.014$, respectively. The reason may be the higher carotenoid concentration extracted from the same amount of dry biomass of R sphaeroides 3757 . Reducing power of both ESG samples and EUT samples increased obviously $(0.242 \pm 0.007$ to $0.743 \pm 0.036$ and $0.128 \pm 0.005$ to $0.437 \pm 0.021$, respectively) with a decrease in the ratio solvent-to-solid from 70 to 20 . The reducing capacity of the ESG samples and EUT samples was enhanced sharply depending on the concentration of dry biomass from R. sphaeroides 3757 . The results indicated that the reducing power of the extracts from different concentrations of dry biomass of R. sphaeroides 3757 showed a dose-dependent effect.

The inhibition of lipid peroxidation is important for prevention of the deterioration of food quality and for prevention of certain human disease processes involving free radicals (Liu et al., 2005). As shown in Fig. 1, the ESG samples showed a more substantial inhibitory effect upon linoleic-acid peroxidation than did the EUT samples. When the ratio solvent-to-solid was 30 , the inhibitory effects of ESG and EUT samples upon linoleic acid peroxidation were $77.6 \% \pm 3.2 \%$ and $55.2 \% \pm 2.3 \%$, respectively. This result may be due to the higher carotenoid concentration extracted from the same amount of dry biomass of R. sphaeroides 3757. As shown in Fig. 1, there was a dosedependent relation between extract concentration and its lipid peroxidation-inhibitory activity; and the lipid peroxidation-inhibitory activities of the extracts increased with the increasing concentrations of dry biomass of R. sphaeroides 3757. As the ratio solvent-to-solid decreased from 60 to 20, the lipid peroxidation-inhibitory activities of both ESG and EUT samples increased noticeably $(35.9 \% \pm 1.4 \%$ to $82.1 \% \pm 3.7 \%$ and $13.1 \% \pm 0.5 \%$ to $65.2 \% \pm 2.8 \%$ ), respectively. This finding indicated that superfine grinding is a much more efficient extraction method in terms of inhibition of lipid peroxidation by the resulting product.

\section{DISCUSSION}

Despite the availability of a variety of natural and synthetic carotenoids, there is currently a renewed 


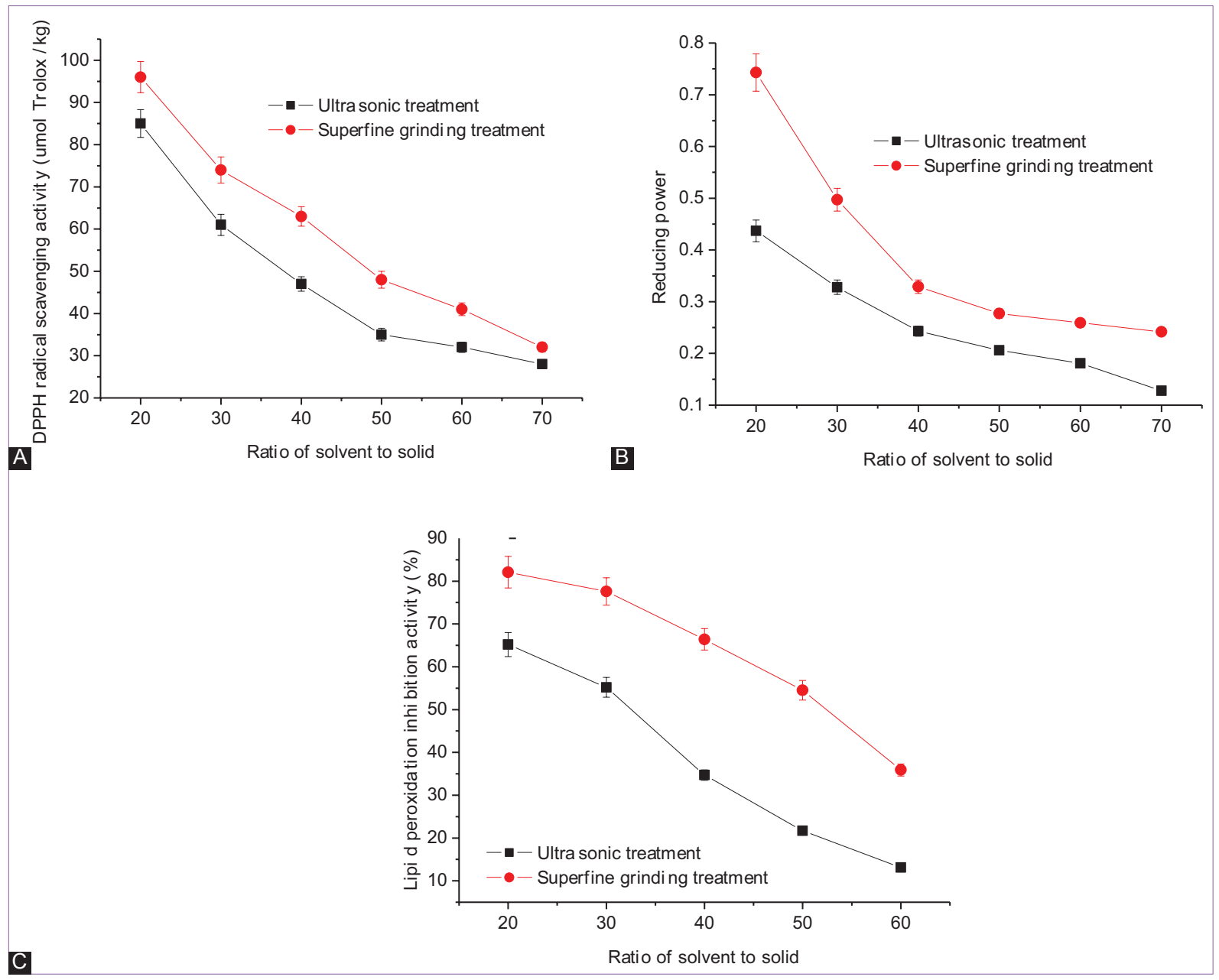

Fig 1. The in vitro antioxidant activity of carotenoids from R. sphaeroides 3757 (A: DPPH radical-scavenging activity; B: reducing power; C: lipid peroxidation inhibitory activity)

interest in microbial sources of pigments because of the problems of seasonal and geographical variability in plant origin, and great demands have been placed on their identification and determination (Sivathanu and Palaniswamy, 2012). The present results reveal the presence of carotenoids including bixin, hydroxyspheroidenone, $3,3^{\prime}, 4^{\prime}$-tetrahydrospirilloxanthin-20-al, and spheroidenone in R. sphaeroides 3757 . This is the first chromatographic analysis of the carotenoid composition from the superfine powder of R. sphaeroides by HPLC-DAD-APCI-MS. Similarly, bixin was identified to be the main carotenoid in annatto seeds by HPLC-DAD-MS/MS, and the antioxidant capacity of bixin results from its ability to quench singlet oxygen, deactivate the excited triplet state of sensitizers and scavenge free radicals (Chiste et al., 2011). HPLCDAD-APCI-MS was a powerful tool for the detection and characterization of carotenoids in rose hip fruit, and 23 carotenoid esters and 21 carotenoids were detected in the unsaponified and saponified extract, respectively (Zhong et al., 2016). The various carotenoids in Scutellaria barbata were identified by HPLC-DAD-APIC-MS using a YMC C30 column, and all-trans-lutein and its cis isomers constituted the largest portion, followed by all-trans- $\beta$-carotene and its cis isomers (Liu et al., 2014). However, none of the above mentioned compositions of carotenoids included hydroxyspheroidenone, 3,3,4,-tetrahydrospirilloxanthin20-al and spheroidenone.

Superfine grinding technology is applied in functional food processing as a novel technology. This is the first report of the antioxidant properties of carotenoid extracts obtained by superfine grinding (ESG) from R. sphaeroides 3757 according to DPPH radical-scavenging activity, reducing power and lipid peroxidation-inhibitory activity. The present results reveal that the antioxidant activity of the carotenoids extracted by superfine grinding from R. sphaeroides 3757 was higher than that by ultrasonic treatment, and that the carotenoids from $R$. sphaeroides 3757 show a significant antioxidant activity in vitro in a concentration-dependent manner, probably because of the higher carotenoid concentration extracted from the same amount of dry biomass of R. sphaeroides 3757. This finding indicated that superfine grinding was a much more efficient extraction method in terms of scavenging of 
DPPH radicals, reducing power and lipid peroxidationinhibitory activity by the resulting product. The superfine grinder we used belongs to ball-milling which is an efficient cost-effective grinding method that is not detrimental to the environment (Zhao et al., 2015). The contents of polyphenols and flavanol in red grape pomace powders (GPP) increased with particle size decreasing during superfine grinding, which could enhance GPP antioxidant activities (Ramachandraiah and Chin, 2016). This is similar to our results. It suggests that superfine grinding technology has a great potential application in food industry, such as functional, manufacture and convenient foods.

The body requires a supplement of dietary antioxidants which can be obtained only by the consumption of an antioxidant-rich diet. Many carotenoids are found to be strong antioxidants because of their unsaturated groups, and much research has been done in the area of antioxidative assays of carotenoids (Fu et al., 2011). Tomato waste extracts which contained considerable amounts of carotenoids (lycopene and $\beta$-carotene) exhibited good antioxidant, and the carotenoid contents exhibited a strong correlation with antioxidant (Stajc 'ic' et al., 2015). This is in accordance with our results. Both composition and antioxidant activity of carotenoids extracted from various samples had been studied recently. Lutein and zeaxanthin were the predominant carotenoids determined using HPLC, and antioxidant activity in both assays increased linearly with total carotenoid content (Giuffrida et al., 2013). These are similar to our results, but the predominant carotenoids in R. sphaeroides 3757 are different from what had been reported above.

\section{CONCLUSIONS}

After separation and purification by silica gel column chromatography and RP-HPLC on a C30 chromatographic column, the four major carotenoids from superfine powders of $R$ sphaeroides 3757 were identified as bixin, hydroxyspheroidenone, 3,3,4,-tetrahydrospirilloxanthin20-al, and spheroidenone by RP-HPLC-APCI-MS. The antioxidant activity of the carotenoids extracted by superfine grinding from dry biomass of $R$. sphaeroides 3757 is higher than that of extracts prepared by ultrasonic treatment according to their in vitro indexes of $\mathrm{DPPH}$ radical-scavenging activity, reducing power and lipid peroxidation-inhibitory activity. These results revealed that carotenoids from R. sphaeroides 3757 show a significant antioxidant activity in vitro in a concentration-dependent manner, and that superfine grinding is the optimal extraction method. Thus, based on the present results, carotenoids from superfine powder of $R$. sphaeroides might be applied in natural antioxidant and functional food with good antioxidant activities.

\section{ACKNOWLEDGMENTS}

This paper was supported by the National Natural Science Foundation of China [grant number 3157020423 and 3157020721], China Scholarship Council Foundation [grant number 201708110129], Beijing Natural Science Foundation [grant number 6173033] and Beijing Municipal Commission of Education [grant number KM20131141 7007 and PXM2013_014209_07_000082]. We also gratefully acknowledge financial support of Scientific Research Project from Facing Characteristic Discipline of Beijing Union University (grant number KYDE40201703).

\section{Disclosure statement}

No potential conflict of interest was reported by the authors.

\section{Authors' contributions}

Zuming Li and Zhihui Bai conceived and designed the experiments; Lina Kong performed the experiments; Lina Kong, Bodi Hui and Zuming Li analyzed the data; Dong Wang contributed materials; Zuming Li and Lina Kong wrote the paper; Xiaoya Shang, Liping Gao, Na Luan and Xuliang Zhuang gave important suggestions and support, Zuming Li, Zhihui Bai and Bodi Hui revised the manuscript.

\section{REFERENCES}

Chi, S. C., D. J. Mothersole, P. Dilbeck, D. M. Niedzwiedzki, H. Zhang, P. Qian, C. Vasilev, K. J. Grayson, P. J. Jackson, E. C. Martin, Y. Li, D. Holten and C. N. Hunter. 2015. Assembly of functional photosystem complexes in Rhodobacter sphaeroides incorporating carotenoids from the spirilloxanthin pathway. BBA Bioenerg. 1847: 189-201.

Chiu, K. H. and W. S. Liu. 2014. Dietary administration of the extract of Rhodobacter sphaeroides WL-APD911 enhances the growth performance and innate immune responses of seawater red tilapia (Oreochromis mossambicus $\times$ Oreochromis niloticus). Aquaculture. 418-419: 32-38.

Chiste, R. C., F. Yamashita, F. C. Gozzo and A. Z. Mercadante. 2011. Simultaneous extraction and analysis by high performance liquid chromatography coupled to diode array and mass spectrometric detectors of bixin and phenolic compounds from annatto seeds. J. Chromatogr. A. 1218: 57-63.

Enzell, C. R., G. W. Francis and S. Liaaen-Jensen. 1969. Mass spectrometric studies of carotenoids 2 . A survey of fragmentation reactions. Acta. Chem. Scand. 23: 727-750.

Francis, G. W. and S. Liaaen-Jensen. 1970. Bacterial carotenoids: 33. Carotenoids of thiorhodaceae: 9. The structures of the carotenoids of the rhodopinal series. Acta. Chem. Scand. 24: 705-2712.

Fu, H. F., B. J. Xie, S. J. Ma, X. R. Zhu, G. Fan and S. Y. Pan. 2011. Evaluation of antioxidant activities of principal carotenoids available in water spinach (Ipomoea aquatica). J. Food Compos. Anal. 24: 288-297.

Giuffrida, D., P. Dugo, G. Torre, C. Bignardi, A. Cavazza, C. Corradini and G. Dugo. 2013. Characterization of 12 capsicum varieties 
by evaluation of their carotenoid profile and pungency determination. Food Chem. 140: 794-802.

Kljak, K. and D. Grbeša. 2015. Carotenoid content and antioxidant activity of hexane extracts from selected Croatian corn hybrids. Food Chem. 167: 402-408.

Lee, S. B., S. H. Yoo, P. Ganesan and H. S. Kwak. 2013. Physicochemical and antioxidative properties of Korean nanopowdered white ginseng. Int. J. Food Sci. Technol. 48: 2159-2165.

Li, X. M., W. H. Peng, Y. Y. Jia, L. Lu and W. H. Fan. 2016. Bioremediation of lead contaminated soil with Rhodobacter sphaeroides. Chemosphere. 156: 228-235.

Liu, J. R., M. J. Chen and C. W. Lin. 2005. Antimutagenic and antioxidant properties of milk-Kefir and soymilk-Kefir. J Agric. Food Chem. 53: 2467-2474.

Liu, H. L., B. H. Chen, T. H. Kao and C. Y. Shiau. 2014. Carotenoids composition in Scutellaria barbata D. Don as detected by high performance liquid chromatography-diode array detection-mass spectrometry-atmospheric pressure chemical ionization. J. Funct. Foods. 8C: 100-110.

Liu, S. L., G. M. Zhang, X. K. Li, P. Wu and J. Zhang. 2015. Enhancement of Rhodobacter sphaeroides growth and carotenoid production through biostimulation. J. Environ. Sci. 33: 21-28.

Ma, H. R., Y. D. Ma, Z. X. Zhang, Z. Y. Zhao, R. Lin, J. M. Zhu, Y. Guo and L. Xu. 2016. L-arginine enhances resistance against oxidative stress and heat stress in Caenorhabditis elegans. Int. J. Environ. Res. Public Health. 13: 1-9.

Manwarning, J., E. H. Evans, G. Britton and D. R. Schneider. 1980. The identification of desmethyl-spheroidenone as a major carotenoid in aerobic cultures of Rhodopseudomonas capsulata. FEBS Lett. 110: 47-49.

Manzano, P., J. Hernández, M. Quijano-Avilés, A. Barragán, I. ChóezGuaranda, R. Viteri and O. Valle. 2017. Polyphenols extracted from Theobroma cacao waste and its utility as antioxidant. Emir. J. Food Agric. 29(1): 45-50.

Ramachandraiah, K. and K. B. Chin. 2016. Evaluation of ballmilling time on the physicochemical and antioxidant properties of persimmon by-products powder. Innov. Food Sci. Emerg. Technol. 37: 115-124.

Rivera, S. M. and R. Canela-Garayoa. 2012. Analytical tools for the analysis of carotenoids in diverse materials. J. Chromatogr. A. 1224: 1-10.

Sánchez, C. V., C. Serrano, M. C. Oliveira, P. Vasilenko, M. Santos and R. M. Sousa. 2016. Differential susceptibility of Morettini pears to blue mold caused by Penicillium expansum. Emir. J. Food Agric. 28(6): 374-380.

Sequeda-Castañeda, L. G., A. R. Barrera-Bugallo, C. Celis, J. Iglesias and L. Morales. 2016. Evaluation of antioxidant and cytotoxic activity of extracts from fruits in fibroblastoma HT1080 cell lines: Four fruits with commercial potential in Colombia. Emir. J. Food Agric. 28(2): 143-151.

Silva, M. M. and F. C. Lidon. 2016. An overview on applications and side effects of antioxidant food additives. Emir. J. Food Agric. 28(12): 823-832.

Sivathanu, B. and S. Palaniswamy. 2012. Purification and characterization of carotenoids from green algae Chlorococcum humicola by HPLC-NMR and LC-MS-APCI. Biomed. Prev. Nutr. 2: $276-282$.

Stajćić, S., G. Ćetković, J. Čanadanović-Brunet, S. Djilas, A. Mandić and D. Četojević-Simin. 2015. Tomato waste: Carotenoids content, antioxidant and cell growth activities. Food Chem. 172: 225-232.

Takaichi, S., K. Furihata and K. Harashima. 1991. Light-induced changes of carotenoid pigments in anaerobic cells of the aerobic photosynthetic bacterium, Roseobacter denitrificans (Erythrobacter species OCh 114): Reduction of spheroidenone to 3,4-dihydrospheroidenone. Microbiology. 155: 473-476.

Takaichi, S. 1993. Usefulness of field desorption mass spectrometry in determining molecular masses of carotenoids, natural carotenoid derivatives and their chemical derivatives. Org. Mass Spectrom. 28: 785-788.

Venetsanou, A., E. Anastasaki, C. Gardeli, P. A. Tarantilis and C. S. Pappas. 2017. Estimation of antioxidant activity of different mixed herbal infusions using attenuated total reflectance Fourier transform infrared spectroscopy and chemometrics. Emir. J. Food Agric. 29(2): 149-155.

Wang, H. D., M. Zhang, G. H. Zhai and H. Jiang. 2012. Comparison of physicochemical and sensory quality of Lentinus edodes granular condiment prepared by different prilling and drying methods. Int. J. Food Sci. Technol. 47: 1265-1271.

Xia, Y. C., F. Bamdad, M. Gänzle and L. Y. Chen. 2012. Fractionation and characterization of antioxidant peptides derived from barley glutelin by enzymatic hydrolysis. Food Chem. 134: 1509-1518.

Yeliseev, A. A. and S. Kaplan. 1997. Anaerobic carotenoid biosynthesis in Rhodobacter sphaeroides 2.4.1: $\mathrm{H}_{2} \mathrm{O}$ is a source of oxygen for the 1-methoxy group of spheroidene but not for the 2-oxo group of spheroidenone. FEBS Lett. 403: 10-14.

Yoo, A. Y., M. Alnaeeli and J. K. Park. 2016. Production control and characterization of antibacterial carotenoids from the yeast Rhodotorula mucilaginosa AY-01. Process Biochem. 51: 463-473.

Zarza-García, A. L., E. Sauri-Duch, D. Raddatz-Mota, L. F. CuevasGlory, L. L. Pinzón-López, F. Rivera-Cabrera and J. A. MendozaEspinoza. 2017. Pharmacological, phytochemical and morphological study of three Mayan accessions of Bixa orellana L. leaves. Emir. J. Food Agric. 29(3): 163-169.

Zhao, X. Y., H. T. Zhu, G. X. Zhang and W. D. Tang. 2015. Effect of superfine grinding on the physicochemical properties and antioxidant activity of red grape pomace powders. Powder Technol. 286: 838-844.

Zhong, L., K. E. Gustavsson, S. Oredsson, B. Głab, J. L. Yilmaz and M. E. Olsson. 2016. Determination of free and esterified carotenoid composition in rose hip fruit by HPLC-DAD-APCI+-MS. Food Chem. 210: 541-550.

Zhu, K. X., S. Huang, W. Peng, H. F. Qian and H. M. Zhou. 2010. Effect of ultrafine grinding on hydration and antioxidant properties of wheat bran dietary fiber. Food Res. Int. 43: 943-948.

Zhuang, H., N. Tang and Y. Yuan. 2013. Purification and identification of antioxidant peptides from corn gluten meal. J. Funct. Foods. 5: 1810-1821. 


\section{SUPPLEMENTAL FIGURES}

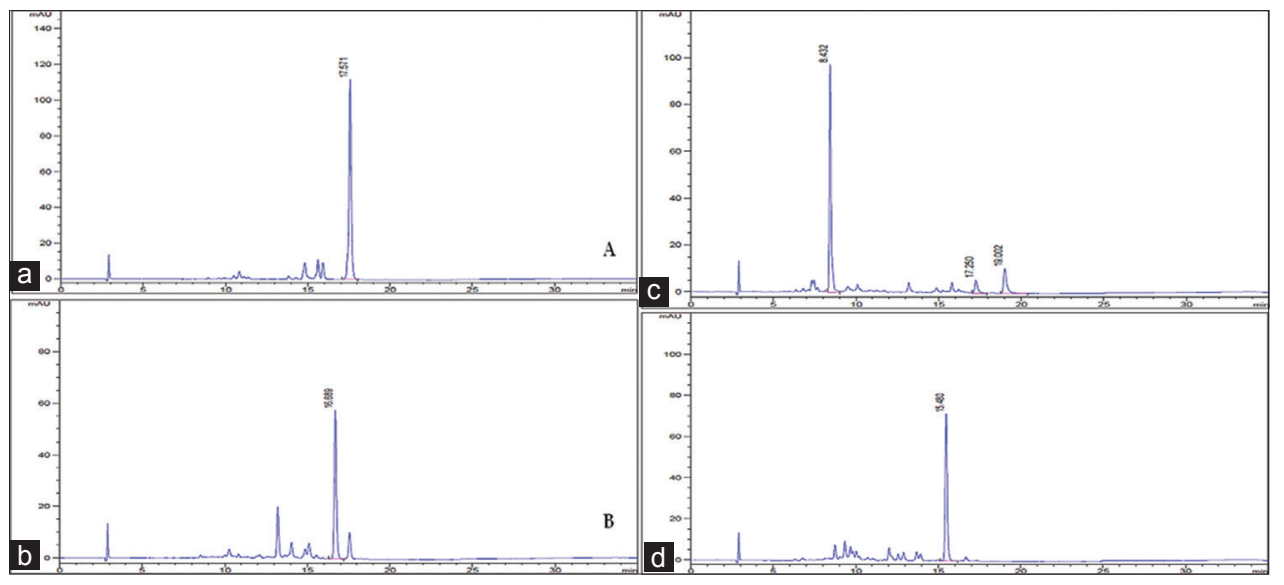

Supplemental Fig 1. HPLC chromatograms of the four main carotenoids from R. sphaeroides 3757 (A: peak 1; B: peak 2; C: peak 3; D: peak 4). Peak identification is shown in Table 1.

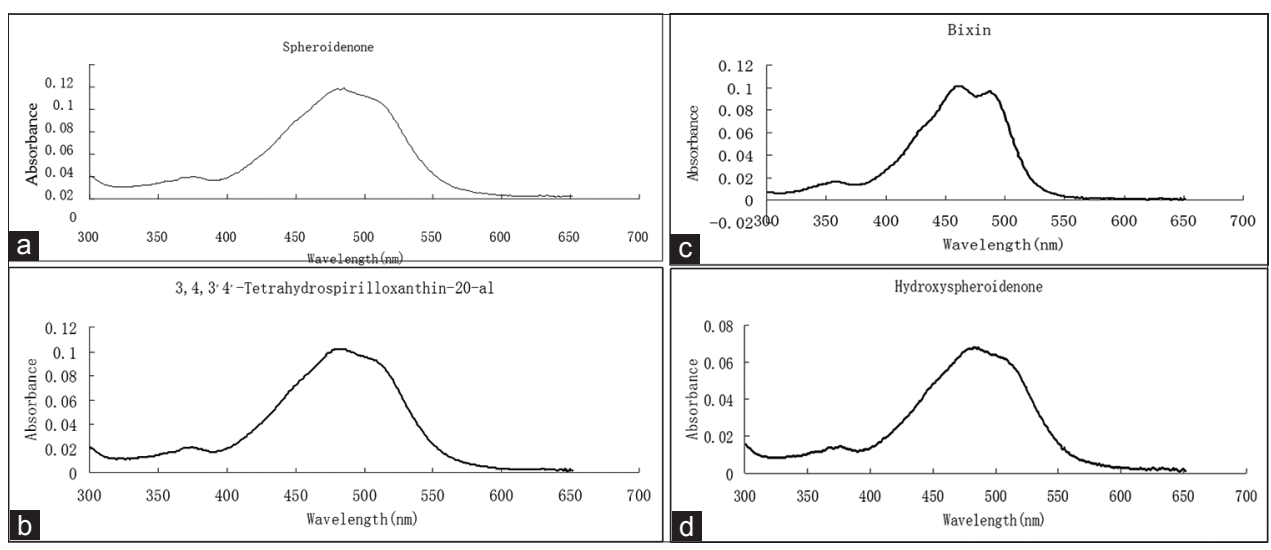

Supplemental Fig 2. UV-vis spectra of the four main carotenoids from $R$. sphaeroides 3757 obtained by HPLC-PDA (A: peak 1; B: peak 2; C: peak 3; D: peak 4). See Table 1 for peak identification. 


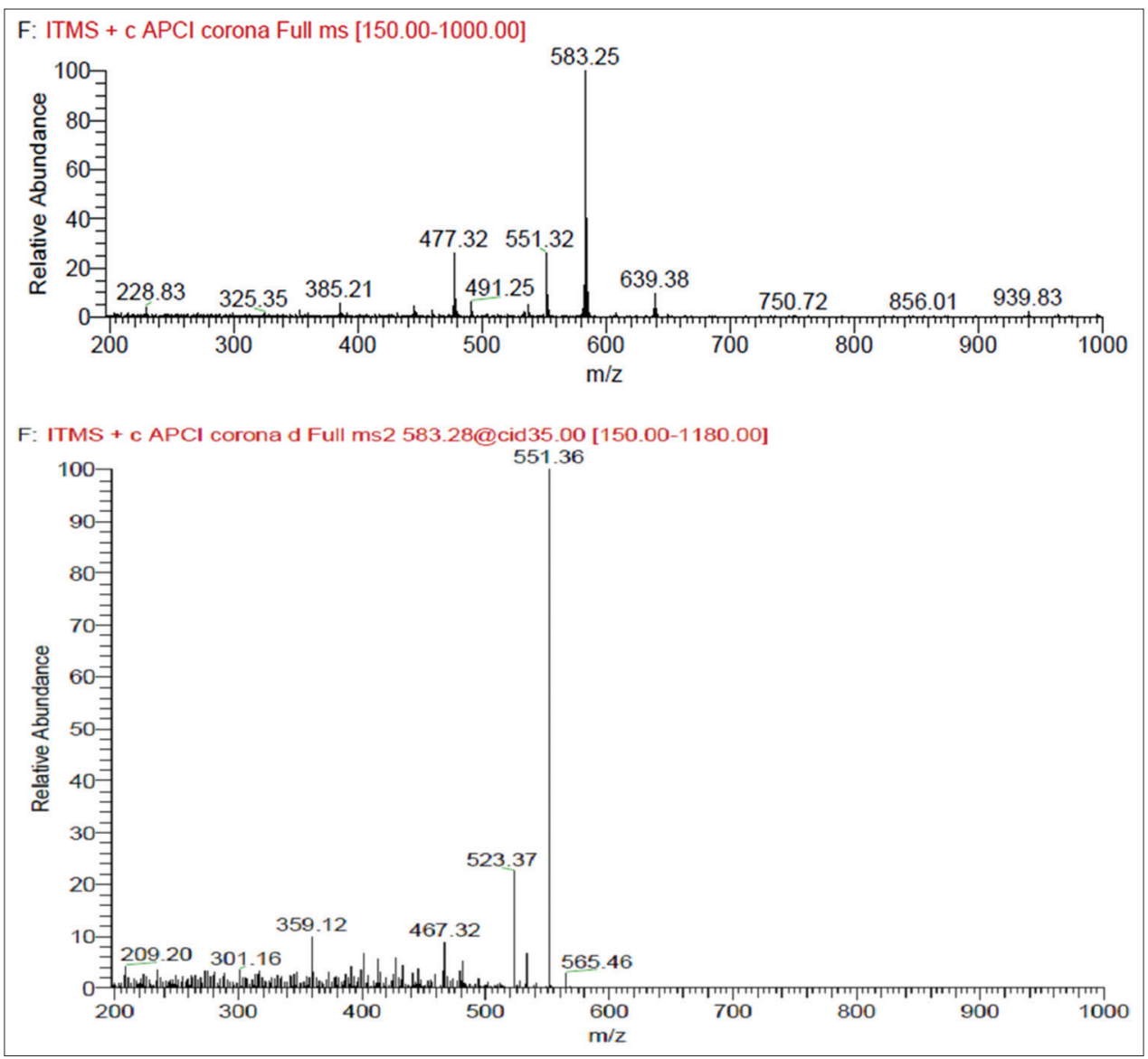

Supplemental Fig 3. APCl mass spectra of spheroidenone (Peak A). 


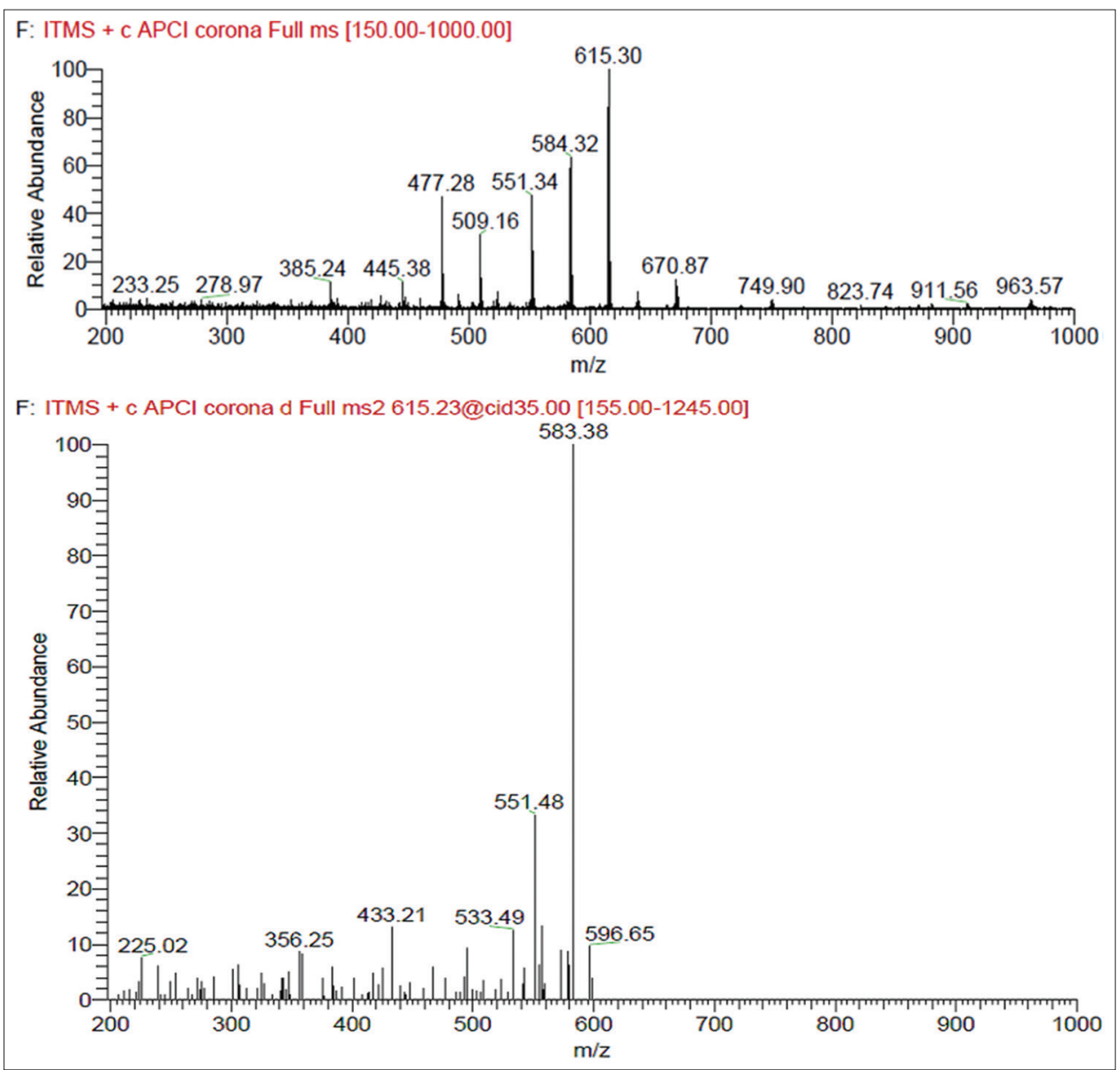

Supplemental Fig 4. APCI mass spectra of 3,4,3',4'-tetrahydrospirilloxanthin-20-al (peak B). 


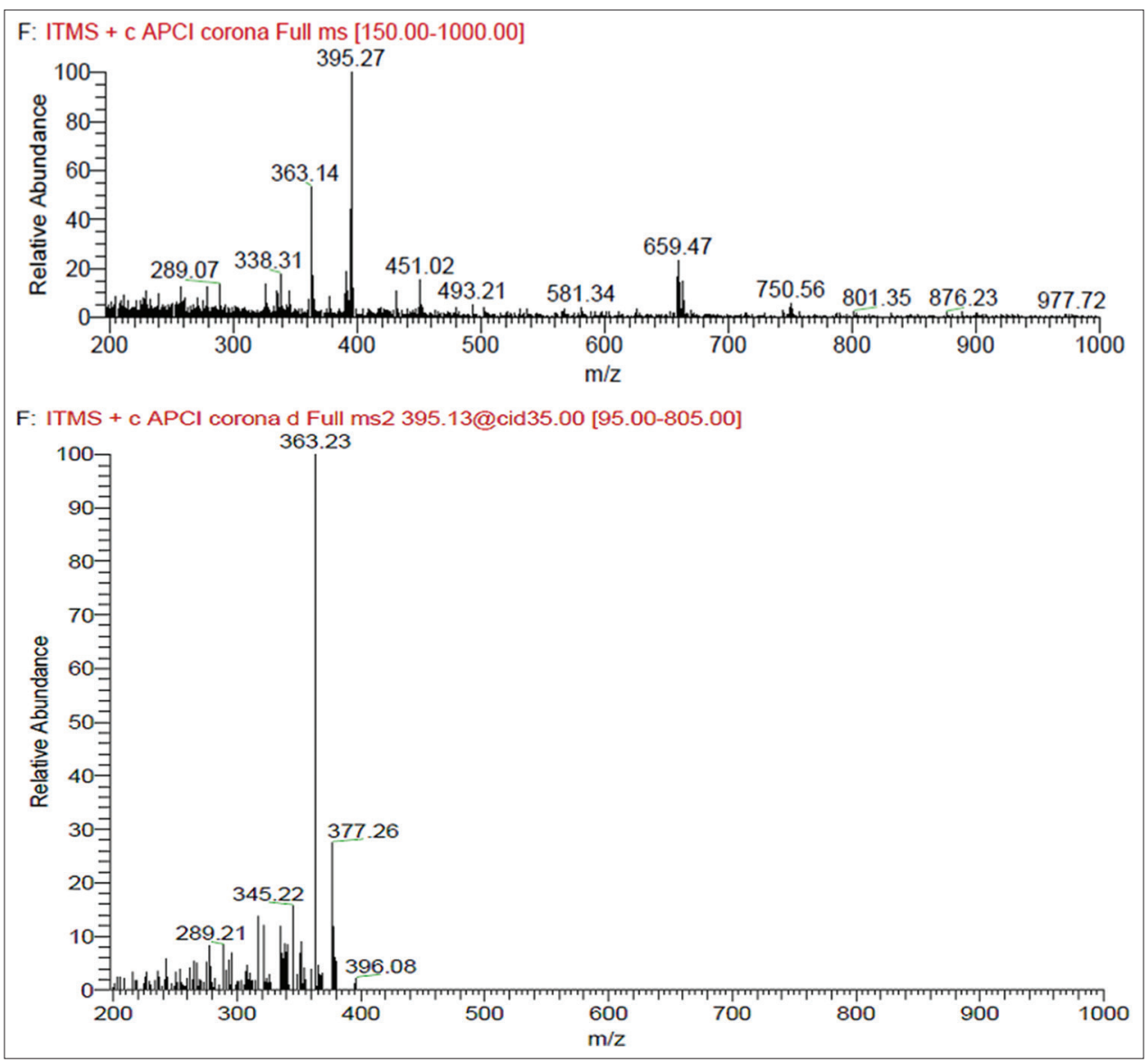

Supplemental Fig 5. APCl mass spectra of bixin (peak C). 


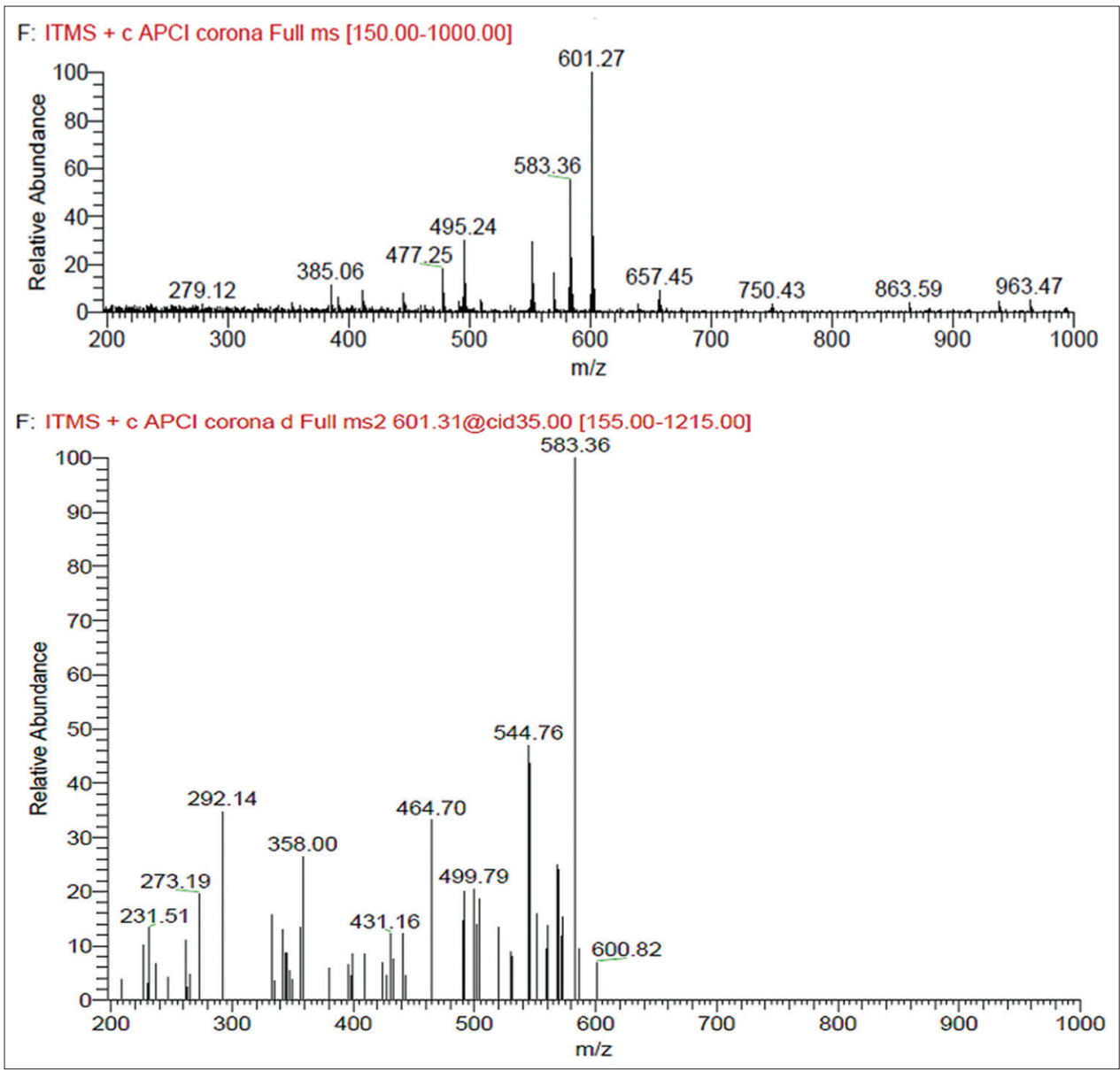

Supplemental Fig 6. APCl mass spectra of hydroxyspheroidenone (peak D). 